\title{
Study on Demography, Imaging and Histologic Classification in Patients with Nasopharyngeal Carcinoma
}

\author{
Nguyen Thanh Hiep ${ }^{1}$, Pham Hong Van ${ }^{2}$ and Nguyen Thi Thai Hoa ${ }^{3 *}$ \\ ${ }^{1}$ Pham Ngoc Thach University of Medicine, Ho Chi Minh City, Vietnam \\ ${ }^{2}$ Introduce National Hospital of Acupuncture, Hanoi, Vietnam \\ ${ }^{3}$ Vietnam National Cancer Hospital, Hanoi, Vietnam \\ *Corresponding author: Nguyen Thi Thai Hoa, Vietnam National Cancer Hospital, Hanoi, Vietnam
}

\section{ARTICLE INFO}

Received: April 25, 2020

Published: May 18, 2020

Citation: Nguyen Thanh Hiep, Pham Hong Van, Nguyen Thi Thai Hoa. Study on Demography, Imaging and Histologic Classification in Patients with Nasopharyngeal Carcinoma. Biomed J Sci \& Tech Res 27(4)2020. BJSTR. MS.ID.004549.

\section{Abstract}

Objectives: To explore the demographic features and histologic classification of nasopharyngeal carcinoma.

Object and Method: 141 patients diagnosed with nasopharyngeal carcinoma based on pathology results were retrospectively analyzed at oncology hospital, from January 2017 to May 2019. The variables include age, gender, and histologic classification of nasopharyngeal carcinoma (non-keratinizing differentiated carcinoma, non-keratinizing undifferentiated carcinoma, neratinizing squamous cell carcinoma)

Results: The study subjects had 141 patients; men accounted for $75.9 \%$, ages 40 $<60$ years old majority (58.9\%). History of smoking and drinking alcohol accounts for a high proportion, respectively, $68.2 \%$ and $47.5 \%$ for men. Local and nearby organs are common reasons for patients to go to the hospital, including neck lymph nodes (74.5\%), nasal symptoms (27.7\%), tinnitus (24.8\%), sputum with blood $(7.8 \%)$. Clinical examination with the above lymph node accounted for the highest proportion (67.4\%). Clinically diagnosed in almost $136 / 141$ cases of nasopharyngeal carcinoma (96.5\%). Non-keratinizing differentiated carcinoma accounted for 54.6\%, 44.0\% Non-keratinizing undifferentiated carcinoma, and 1.4\% Keratinizing squamous cell carcinoma.

Conclusion: Nasopharyngeal carcinoma is a fairly common malignant disease histopathological classification that helps for the selection of treatments and prognosis.

\section{Short Communication}

Nasopharyngeal carcinoma is a malignant tumor that originates from the epithelial lining of the nasopharynx area. It is common cancer in the southern indigenous population of China, Southeast Asia, the Arctic region, the Middle East as well as North America. According to statistics of Pham Hoang Anh 1996-1997 [1], Vietnam ranked 4th in the world in the incidence of pharyngeal cancer after Hong Kong, Singapore, Shanghai-China. According to the statistics of Ellen T. Chang and Hans-Olov Adami, from 1993-1997 in Hanoi, the incidence of pharyngeal cancer was 16 per 100,000 people, and from 1995-1998 in Ho Chi Minh City the incidence Archopharynx cancer is 6.5 per 100,000 people [2]. Nasopharyngeal carcinoma is one of the five most common cancers in our country (cancers of the lung, stomach, breast, uterus, oropharynx) [3]. Because of the deep anatomical characteristics of the skull as well as earlystage symptoms, which are often poor and easily confused with otolaryngology, nasopharyngeal carcinoma is often overlooked in the initial diagnosis. Therefore, nasopharyngeal carcinoma is usually diagnosed late when the disease has been stage III, IV [4].

\section{Materials and Methods}

Patients diagnosed with nasopharyngeal carcinoma are treated at Ho Chi Minh City Oncology Hospital from January 2017 to May 
2019. Diagnosed with pharyngeal cancer by histopathological results. Data are entered and analyzed statistically by SPSS 16.0 software. Steps to take:

i. Step 1: Make a list of cases diagnosed with nasopharyngeal carcinoma diagnosed at oncology hospital, Ho Chi Minh city, using pathological results.

ii. Step 2: Statistics and data processing.

\section{Results}

(Tables 1-6).

Table 1: Distribution of research subjects by age and gender $(n=141)$.

\begin{tabular}{|c|c|c|c|}
\hline \multicolumn{2}{|c|}{ General features } & Number of Patients(n) & Rate (\%) \\
\hline \multirow{3}{*}{ Age group } & $20-<40$ & 33 & 23.4 \\
\hline & $40-<60$ & 83 & 58.9 \\
\hline & $60-80$ & 25 & 17.7 \\
\hline \multicolumn{2}{|c|}{ The average age } & \multicolumn{2}{|c|}{$48,9 \pm 12,3$ (minimum 23 , maximum 80 ) } \\
\hline
\end{tabular}

Note: The study subjects had 141 patients, men accounted for $75.9 \%$, ages $40-<60$ years old majority (58.9\%), lowest age 23 , highest 80 years old, average $48.9 \pm 12.3$.

Table 2: Historical characteristics.

\begin{tabular}{|c|c|c|}
\hline History & Tần số & Tỉ lệ (\%) \\
\hline Smoking (for men) & $73 / 107$ & 68.2 \\
\hline Drinking alcohol (for men) & $67 / 107$ & 47.5 \\
\hline Families with people with nasopharyngeal carcinoma & $8 / 141$ & 5.7 \\
\hline
\end{tabular}

Note: Men who have a history of smoking and drinking alcohol account for a high proportion, respectively, $68.2 \%$ and $47.5 \%$. There are 8 cases (5.7\% of the 141 patients) who have family members who have nasopharyngeal carcinoma.

Table 3: Reason for admission to the hospital.

\begin{tabular}{|c|c|c|}
\hline Reason for Admission to the Hospital & Number of Patients (n) & Rate (\%) \\
\hline Tinnitus & 35 & 24.8 \\
\hline Nasal symptoms & 39 & 74.5 \\
\hline Lymph nodes & 105 & 8.5 \\
\hline Neurological symptoms & 12 & 0.7 \\
\hline Nasopharyngeal carcinoma is not treated & 1 & 7.1 \\
\hline Headache & 10 & 7.8 \\
\hline Sputum spotting blood & 11 & 0.7 \\
\hline Hoarseness & 1 & 0.7 \\
\hline Double look & 1 & 1.4 \\
\hline Blurred vision & 2 & 0.7 \\
\hline Sore eyes & 1 & 0.7 \\
\hline Lisp & 1 & 5 \\
\hline
\end{tabular}

Note: Local and nearby organs are common reasons for patients to go to the hospital, including neck lymph nodes (74.5\%), nasal symptoms $(27.7 \%)$, tinnitus $(24.8 \%)$, sputum with blood $(7.8 \%)$. Besides, symptoms related to the central nervous system also accounted for a significant proportion such as headache $7.1 \%$, other neurological symptoms $8.5 \%$. There were 32 cases of lymph nodes on the right $(30.5 \%), 34$ nodes on the left (32.4\%), 39 cases of lymph nodes on both sides $(37.1 \%)$

Table 4: Clinical lymph node position.

\begin{tabular}{|c|c|c|}
\hline Lymph Node Position & Number of Patients (n) & Rate (\%) \\
\hline Lymph node under the chin & 8 & 7.6 \\
\hline Above cervical lymph node & 95 & 90.5 \\
\hline Middle cervical lymph node & 41 & 39 \\
\hline Lower cervical lymph node & 20 & 19 \\
\hline
\end{tabular}




\begin{tabular}{|c|c|c|}
\hline Posterior cervical lymph node & 17 & 16.2 \\
\hline Anterior cervical lymph node & 1 & 1 \\
\hline Total & 105 & 100 \\
\hline
\end{tabular}

Note: Clinical examination with the above lymph node accounted for the highest proportion (67.4\%), followed by the middle lymph nodes $(29.1 \%)$, lower lymph nodes $(14.2 \%)$.

Table 5: Clinical diagnosis.

\begin{tabular}{|c|c|c|}
\hline Clinical Diagnosis & Number of Patients (n) & Rate (\%) \\
\hline Nasal cavity cancer & 2 & 1.4 \\
\hline Nasopharyngeal carcinoma & 136 & 96.5 \\
\hline Maxillary sinus carcinoma & 1 & 0.7 \\
\hline Lymphoma & 2 & 1.4 \\
\hline Total & 141 & 100 \\
\hline
\end{tabular}

Note: Clinically diagnosed in almost 136/141 cases of nasopharyngeal carcinoma (96.5\%).

Table 6: Anatomical diagnosis.

\begin{tabular}{|c|c|c|}
\hline Results of Anatomy & Number of Patients (n) & Rate (\%) \\
\hline Keratinizing squamous cell carcinoma & 2 & 1.4 \\
\hline Non-keratinizing differentiated carcinoma & 77 & 54.6 \\
\hline Non-keratinizing undifferentiated carcinoma & 62 & 44 \\
\hline Total & 141 & 100 \\
\hline
\end{tabular}

Note: Non-keratinizing differentiated carcinoma accounted for $54.6 \%, 44.0 \%$ Non-keratinizing undifferentiated carcinoma, and $1.4 \%$ Keratinizing squamous cell carcinoma.

\section{Discussion}

According to the results in Table 1, the nasopharyngeal carcinoma rate gradually increases from the age of 20-40 years, reaching the highest peak in the age group 40-60 years, accounting for $58.9 \%$ and then the age group $60-80$ years accounting for the rate of $17.7 \%$. The youngest is 23 , and the oldest is 80 years old. With our research results, the age group most often affected by nasopharyngeal carcinoma is the age group of 40-60 years old, with a rate of $58.9 \%$. This result is higher than that of author Dang Thanh (40\%) [5] and lower than that of Pham Nguyen Tuong (65.3\%) [6]. According to author Nguyen Trong Minh, et al. [7] the age group 40-50 years old has a high incidence of disease [7]. According to author Ngo Ngoc Lien, the common age group is 30-50 years old [8]. According to author Zong et al., the common age is $40-59$ years old [9]. The age group of prostate cancer patients in our study is quite consistent with the above authors. According to the results in Table 1, the prevalence in men is $107 / 141$, accounting for $75.9 \%$, and the prevalence in women is $34 / 141$, accounting for $24.1 \%$. Thus, the incidence of infection in men is about three times more than women. According to author Tran Thi Hop, the male / female frequency is 2.5 / 1 [10], according to author Li J.X, the male / female frequency is $2.7 / 1$ [11]. Our research results are relatively consistent with the research of the two authors. The results in Table 2 show that the proportion of male smokers making up $68.2 \%$ and drinking alcohol accounts for $47.5 \%$. According to Abdulamir, et al. The proportion of male smokers making up $85.7 \%$ and having alcohol accounted for $42.8 \%$ [12].

Our research results are quite consistent with the author's study. According to the research results in Table 3, the reason for hospitalization due to cervical lymph nodes accounts for the highest proportion, 74.5\%. According to the authors Razek A and King A, the nasopharyngeal carcinoma often metastases of neck lymph nodes at the rate of $75-90 \%$ [13]. Thus, when signs of cervical lymph nodes appear, patients should be examined and diagnosed early. Reasons for hospitalization due to tinnitus accounted for 24.8\%. According to author Nguyen Thi Bich Thuy and author Phung Hung, tinnitus symptoms were 16\% [14] and 76.74\% [15], respectively. Our research results are relatively consistent with the results of author Nguyen Thi Bich Thuy and much lower than that of Phu Hung. When the tumor is located on the side of the dome, it narrows and clears the Eustache and causes tinnitus. Nasal symptoms in our study accounted for $27.7 \%$. According to Phung Hung, the symptoms of nasal congestion were 54.84\% [15]. Our research results are still lower than the authors' results. According to our research, the symptoms of cranial nerve damage accounts for 8.5\%. According to author Nguyen Thi Bich Thuy, the symptoms of cranial nerve damage accounts for $8 \%$ [14]. Our research results are relatively consistent with the results of the above author. According to some authors, the probability of detecting cervical lymph nodes is $85-90 \%$, of which the lymph nodes of the two sides account for 
$50 \%$ [16]. In our research results, the clinical findings of cervical lymphadenopathy were $74.4 \%$, of which the cervical lymph nodes were $37.1 \%$. According to author Skinner, et al., Bilateral lymph nodes have a detection rate of $43 \%$ [16].

Our research results are relatively consistent with the results of the above author. The clinical prevalence of lymph node not detected was $25.6 \%$. According to author Dang Thanh, the clinical examination did not see cervical lymph nodes accounting for $20 \%$ [5]. Our research results are quite consistent with the above author. According to the results of Table 4, the lymph node groups along the carotid vascular bundles (II, III and IV) account for a high proportion (the upper one accounts for $90.5 \%$, the middle one is $39 \%$, and the lower one is 19\%.) et al. (2004), the upper lymph node group accounted for $95.5 \%$, the middle scene was $60.7 \%$, the lower scene was $22.5 \%$ [16]. Our research results compared with the above authors show that the metastatic lymph nodes are mainly in the carotid group, especially in the upper lymph node group with a very high rate. Non-keratinizing differentiated carcinoma accounted for the highest proportion (54.6\%), followed by non-keratinizing undifferentiated carcinoma $(44.0 \%)$ and keratinizing squamous cell carcinoma (1.4\%). According to authors Razek A and King A, the non-keratinizing undifferentiated carcinoma was $95 \%$, the nonkeratinizing differentiated carcinoma was 3\%, and the keratinizing squamous cell carcinoma was $2 \%$ [13]. According to the author Ngo Huu Thuan, the non-keratinizing undifferentiated carcinoma accounted for $94.7 \%$. The keratinizing squamous cell carcinoma was $5.3 \%$ [17]. Our results agree with the two authors on the low rate of keratinizing squamous cell carcinoma. The difference is that because we limited the sample before and after radiation therapy, so we lost a lot of samples not treated or treated by other methods, which made the difference in the proportion of pathological tissues in the study.

\section{Conclusion}

The study subjects had 141 patients. Men accounted for $75.9 \%$, ages 40- $<60$ years old majority. History of smoking and drinking alcohol accounts for a high proportion for men. Clinical examination with the above lymph node accounted for the highest proportion. Clinically diagnosed in almost cases of nasopharyngeal carcinoma Non-keratinizing differentiated carcinoma accounted for $54.6 \%$, $44.0 \%$ Non-keratinizing undifferentiated carcinoma, and $1.4 \%$ Keratinizing squamous cell carcinoma.

\section{References}

1. Pham Hoang Anh (2002) The situation of cancer in Hanoi in the 19961999 period. Journal of Practical Medicine. p. 4-12.

2. ET Chang, HO Adami (2006) The enigmatic epidemiology of nasopharyngeal carcinoma. Cancer Epidemiol Biomarkers Prev 15(10): 1765-1777.

3. Nguyen Ba Duc (2012) Diagnosis and treatment of cancer. Medical Publishing House. pp. 100-112.

4. Mai Trong Khoa, Tran Dinh Ha, Phan Si An (2008) The role of SPECT radiography in cancer monitoring. Medical journal.

5. Dang Thanh (2000) Study of clinical, subclinical characteristics and results of treatment of pharyngeal cancer at Hue Central Hospital. Master's thesis in medicine, Hue College of Medicine, Hue University.

6. Nguyen Huu Thoi, Pham Nguyen Tuong (2003) Evaluating the results of treatment of local recurrence cancer in the area. Oncology Symposium, Ho Chi Minh City Journal of Medicine 7(4): 88-93.

7. Nguyen Lam Giang, Nguyen Trong Minh (2004) Cancer of the nasopharynx hong. Topic Overview, Ho Chi Minh City Medical Journal 8(1): 7-12.

8. Ngo Ngoc Lien (2006) Cancer of the nose and throat. Pathology of Otolaryngology, Medical Publishing House. pp. 204-210.

9. Jun Ma, Sumei Cao (2010) The Epidemiology of Nasopharyngeal Carcinoma. In: Lu JJ, Cooper JS, Lee AWM (Eds.), Nasopharyngeal Cancer: Multidisciplinary Management. Springer Berlin Heidelberg, Berlin, Heidelberg. p. 1-7.

10. Tran Thi Hop (2001) Nasopharyngeal cancer. Lecture on Oncology, Medical Publishing House. pp. 97-101.

11. JX Li, TX Lu, Y Huang, F Han (2012) Clinical characteristics of recurrent nasopharyngeal carcinoma in high-incidence area. Scientific World Journal. pp. 719754.

12. AS Abdulamir, RR Hafidh, N Abdulmuhaimen, F Abubakar, KA Abbas (2008) The distinctive profile of risk factors of nasopharyngeal carcinoma in comparison with other head and neck cancer types. BMC Public Health 8(1): 400.

13. A Abdel Khalek Abdel Razek, A King (2012) MRI and CT of nasopharyngeal carcinoma. AJR Am J Roentgenol 198(1): 11-18.

14. Nguyen Thi Bich Thuy (2003) Chemotherapy of metastatic pharyngeal cancer at Cancer Hospital in Ho Chi Minh City 1995-1999. Oncology Symposium, Ho Chi Minh City Journal of Medicine 7(4): 100-103.

15. Phung Hung (2010) Study on computerized tomography images of pharyngeal cancer. Master's thesis in medicine, Hue University of Medicine and Pharmacy, Hue University, Vietnam.

16. Simon S Lo, Jiade J Lu (2010) Natural History, Presenting Symptoms, and Diagnosis of Nasopharyngeal Carcinoma. In: Lu JJ, Cooper JS, Lee AW (Eds.), Nasopharyngeal Cancer: Multidisciplinary Management. Springer Berlin Heidelberg, Berlin, Heidelberg. P. 41-51.

17. Ngo Huu Thuan (2014) Study of multi-array computerized tomography imaging images in the diagnosis of pharyngeal cancer. Functional thesis level II, Hue College of Medicine and Pharmacy. 
ISSN: 2574-1241

DOI: 10.26717/BJSTR.2020.27.004549

Naim Morina. Biomed J Sci \& Tech Res

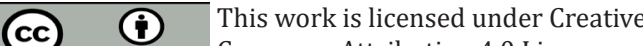

Submission Link: https://biomedres.us/submit-manuscript.php

$\begin{array}{ll}\text { BIOMEDICAL } & \text { Assets of Publishing with us } \\ \text { RESEARCHES } & \text { - Global archiving of articles } \\ \text { - Immediate, unrestricted online access }\end{array}$

